Table 1 Dye test titres, IgM levels, IgG avidity, and total immunoglobulin levels in serum $(S)$ and vitreous $(V)$ samples

\begin{tabular}{llllll}
\hline $\begin{array}{l}\text { Time (weeks) after } \\
\text { onset of symptoms }\end{array}$ & $\begin{array}{l}\text { Dye test } \\
\text { titre }\end{array}$ & $\begin{array}{l}\text { Dye test } \\
(I U / m l)\end{array}$ & $\begin{array}{l}\text { IgM } \\
(I U)\end{array}$ & $\begin{array}{l}\text { IgG } \\
\text { avidity }\end{array}$ & $\begin{array}{l}\text { Total Ig } \\
\text { (g) }\end{array}$ \\
\hline $12(\mathrm{~S})$ & $1 / 256$ & 125 & 75 & $32 \%$ & NT \\
$22($ S) & $1 / 256$ & 125 & 55 & $36 \%$ & NT \\
$37($ S) & $1 / 256$ & 125 & 36 & NT & $12 \cdot 100$ \\
37 (V) & $1 / 16$ & 8 & NT & NT & $0 \cdot 237$ \\
\hline
\end{tabular}

NT= not tested

months previously. An avidity of $40 \%$ is usually seen in infections acquired more than 6 months previously. The Goldmann-Witmer coefficient, ${ }^{3}$ the quotient of relative amounts of toxoplasmal antibodies in vitreous and serum, was 3.19:1. Baarsma $e t a l^{5}$ consider a coefficient of more than 3 to be a positive result, consistent with localised active antibody production in the vitreous, suggesting active disease.

Our patient had no clinical or laboratory findings to suggest any underlying immunological abnormality. It has been suggested that symptomatic acquired toxoplasmosis affecting the eye is rare in the immunocompetent host, although cases have been reported. ${ }^{6}$ Virtually all reported cases had associated systemic features such as lymphadenopathy. Our provisional diagnosis of acquired toxoplasmosis affecting the eye was extremely unusual in an immunocompetent 60 -year-old person with no other symptoms. The presence of toxoplasmal DNA in the vitreous sample, demonstrated by PCR was strong additional supporting evidence.

Part of this work was funded by a research grant from the Toxoplasmosis Trust.

1 Aouizerate F, Cazenave J, Poirier L, Verin P, Cheyrou A, Begneret $\mathrm{J}$, et al. Detection of Toxoplasma gondii in aqueous humour by polymerase chain reaction. Br F Ophthalmol 1993; 77: 107-9.

2 Burg L, Grover CM, Pontethy P, Boothroyd J. Direct and sensitive detection of pathogenic protozoan Toxoplasma sensitive detection of pathogenic protozoan Toxoplasma
gondii by polymerase chain reaction. $\mathcal{F}$ Clin Microbiol 1989; gondit by poly $1787-92$.

3 Witmer R. Clinical implications of aqueous humor studies in uveitis. Am F Ophthalmol 1978; 86: 39-45.

4 Joynson DHM, Payne RA, Rawal BIC. Potential role of IgG avidity for diagnosing toxoplasmosis. $\mathcal{F}$ Clin Pathol 1990; 43: 1032-3.

5 Baarsma GS, Luyendijk L, Kijlstra A, de Vries J, Peperkamp $\mathrm{E}$, Mertens DAE, et al. Analysis of local antibody production in vitreous humor of patients with severe uveitis. Am $\mathcal{F}$ Ophthalmol 1991; 112: 147-50.

6 Saari M, Vourre I, Niminem H. Acquired toxoplasma chorioretinitis. Arch Ophthalmol 1976; 94: 1485-90.

\title{
Aspergillus niger as an unusual cause of scleritis and endophthalmitis
}

\author{
Martine J Jager, James Chodosh, Andrew J W Huang, Eduardo C Alfonso, William W \\ Culbertson, Richard K Forster
}

Bascom Palmer Eye Institute, University of Miami, Miami, USA M J Jager

J Chodosh

A J W Huang

E C Alfonso

W W Culbertson

R K Forster

Department of Ophthalmology, Leiden University, Leiden, the Netherlands

$M \mathrm{~J}$ Jager

Correspondence to:

Martine J Jager, MD

Department of

Ophthalmology, AZL, Leiden

University, PO Box 9600, 2300

RC Leiden, The Netherlands.

Accepted for publication

8 February 1994
Ocular infections with Aspergillus species are associated with keratitis and sporadically with endophthalmitis. In addition, Aspergillus is an uncommon cause of infectious scleritis. We describe here a patient who developed an $A$ niger infection of the sclera possibly caused by drug abuse or automutilation. The infection progressed to endophthalmitis. No similar infection with $A$ niger has been reported to our knowledge.

\section{Case report}

A 35-year-old white woman presented with a 3 month history of a painful red right eye associated with severe right sided headache. Earlier diagnostic evaluation included a computed tomography scan of the head and paranasal sinuses, lumbar puncture, chest radiogram, serological tests for syphilis, Lyme disease, collagen vascular disease, and rheumatoid arthritis, as well as a tuberculin skin test. All results were unremarkable. Treatment with prednisone ( $80 \mathrm{mg} /$ day) for presumed idiopathic scleritis was begun with initial improvement, but had to be discontinued because of systemic side effects.

The patient was referred to the Bascom Palmer Eye Institute in February 1992 with a recurrence of the pain around the right eye. Examination showed a visual acuity of 20/20 in both eyes. A focal area of anterior scleritis with a bluish tinge was noted in the inferotemporal quadrant of the right eye. Ophthalmic examination was otherwise normal in both eyes. A subconjunctival injection of $0.5 \mathrm{ml}$ triamcinolone $(40 \mathrm{mg} / \mathrm{ml})$ was placed adjacent to the scleritis, which led to improvement. The patient subsequently received periocular steroid injections every 3 weeks, given by her private ophthalmologist.

Ten months later she was referred again, this time because of decreased vision and an unusual anterior chamber infiltrate in the right eye, for which she had been treated with prednisolone acetate $1 \%$ every hour and diclofenac sodium $0 \cdot 1 \%$, four times a day, without improvement. Visual acuity was 20/70 in her right eye, and the anterior chamber showed fluffy material 


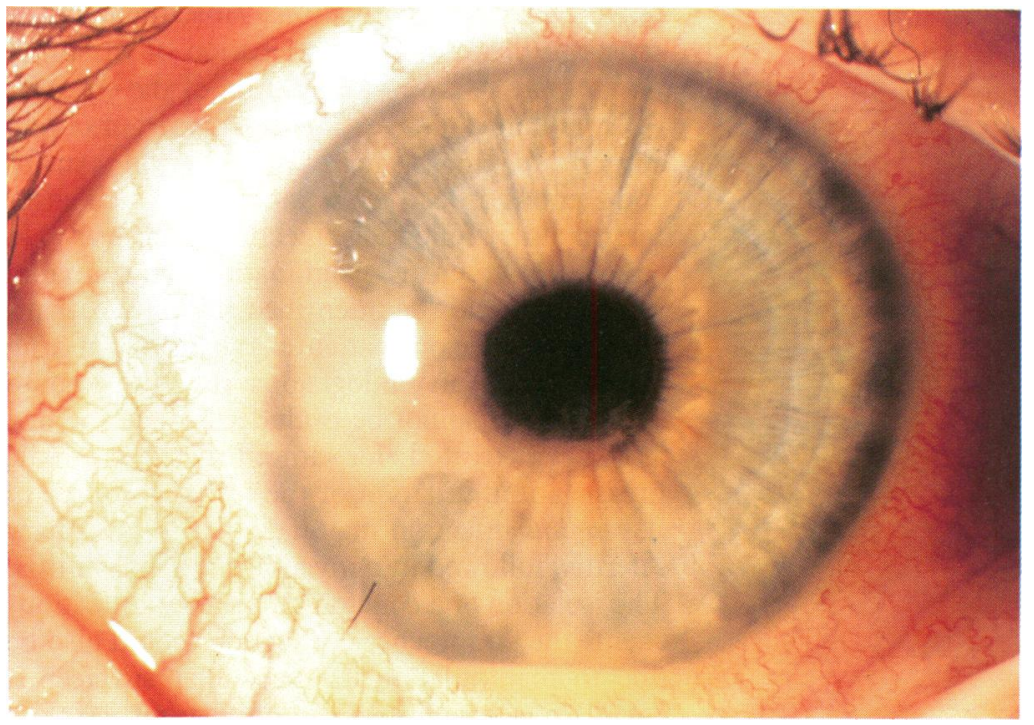

Figure 1. Fluffy material in the anterior chamber, with attachment to the iris and chamber angle. A suture is seen at the site of the earlier paracentesis (14 December, 1992).

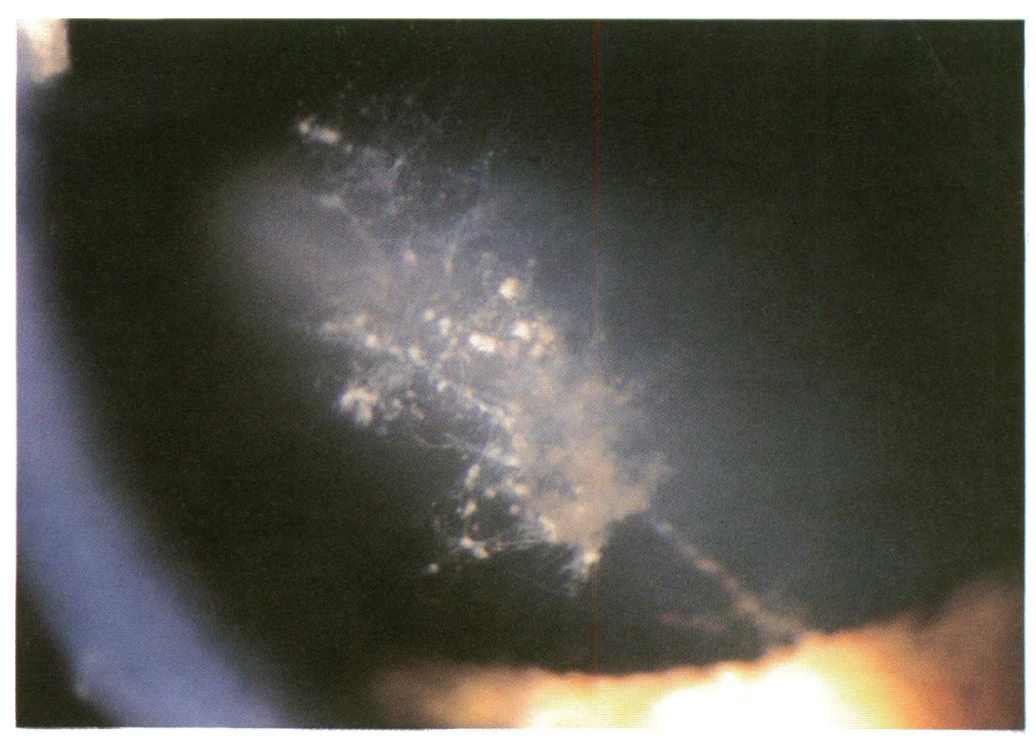

Figure 2 Crystalliform material remained attached to iris and anterior surface of the lens (17 December, 1992) following antibiotic treatment.

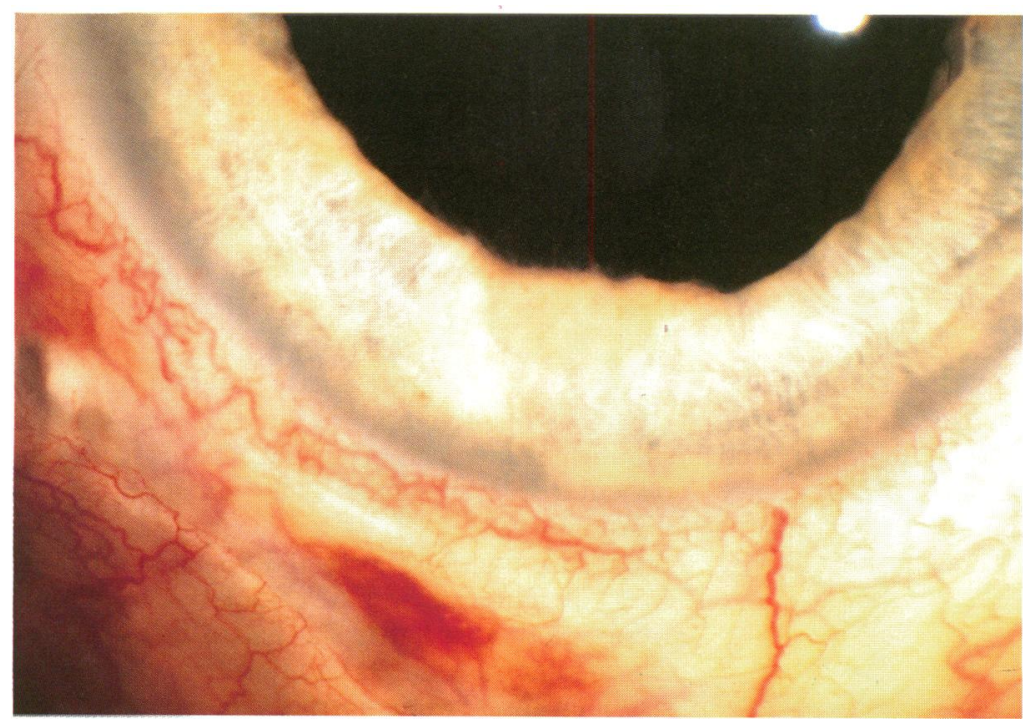

Figure 3 Scleral melt at the limbus, and recurrence of intraocular feathery material attached to the inferior pupillary border (26 fanuary, 1993). attached to the temporal angle of the anterior chamber and the adjacent iris. There were some cells in the anterior chamber without a hypopyon. A diagnostic anterior chamber paracentesis was performed, while treatment with topical prednisolone acetate $1 \%$ was continued. The left eye did not show any abnormalities. Two days later the visual acuity of the right eye had decreased to 20/200. and the anterior chamber showed branching crystalline material (Fig 1). Treatment was begun with topical fortified vancomycin $(50 \mathrm{mg} / \mathrm{ml})$ and ceftazidime $(5 \%)$ every hour, periocular injections of vancomycin $(25 \mathrm{mg})$ and ceftazidime (100 mg), and intravenous cefazolin ( $1 \mathrm{~g}$ every 8 hours). The anterior chamber aspirate grew Streptococcus sanguis in thioglycollate broth only, and the ceftazidime drops were stopped. Following her discharge, intravenous cefazolin was changed to oral cephalexin $500 \mathrm{mg}$ four times a day.

The patient's symptoms and ocular signs improved initially, and the material in the anterior chamber became more crystalline although it did not disappear (Fig 2). The material in the anterior chamber subsequently developed into a net-like infiltrate which appeared to involve the iris and the lens capsule. A diagnostic and therapeutic pars plana lensectomy and vitrectomy were performed: smears of the lens capsule revealed hyphae and cultures grew $A$ niger on all plates. Intravitreal injections of amphotericin B (0.005 mg), vancomycin (1.0 $\mathrm{mg})$, and dexamethasone $(0.4 \mathrm{mg})$ were given at the time of vitrectomy. Subconjunctival injections of $25 \mathrm{mg}$ vancomycin and $12 \mathrm{mg}$ dexamethasone were also given. In the following days, the patient received two additional intravitreal injections of amphotericin $B$, oral fluconazole ( $200 \mathrm{mg}$ twice a day), and topical fluconazole $2 \%$ every 2 hours. However, the infection progressed with a recurrence on the iris and a perilimbal scleritis on the involved side (Fig 3). Despite subsequent corneoscleral resection with hemi-iridocyclectomy and patch graft, eventually an enucleation had to be performed for intractable pain and recurrent infection. Histopathology of the specimens from the corneoscleral resection as well as from the enucleated globe revealed hyphae within the sclera (Fig 4). The pain continued to be severe following the enucleation but may have been due to a drug addiction problem: at this time information was obtained that our patient had been treated at a drug rehabilitation centre for drug misuse several years before the development of scleritis. She also had a history of breast automutilation.

\section{Comment}

No previous reports of scleritis due to $A$ niger have been published, and very few cases of any type of Aspergillus scleritis without prior surgery or trauma have been reported. ' We can speculate about the possible causes of the Aspergillus scleritis in our patient. Possibilities include: (1) endogenous spread of an Aspergillus infection from elsewhere in the body, which is relatively common in injecting drug users ${ }^{2}$; (2) local trauma; and (3) iatrogenic inoculation of fungus.

Iatrogenically induced cases of Aspergillus 


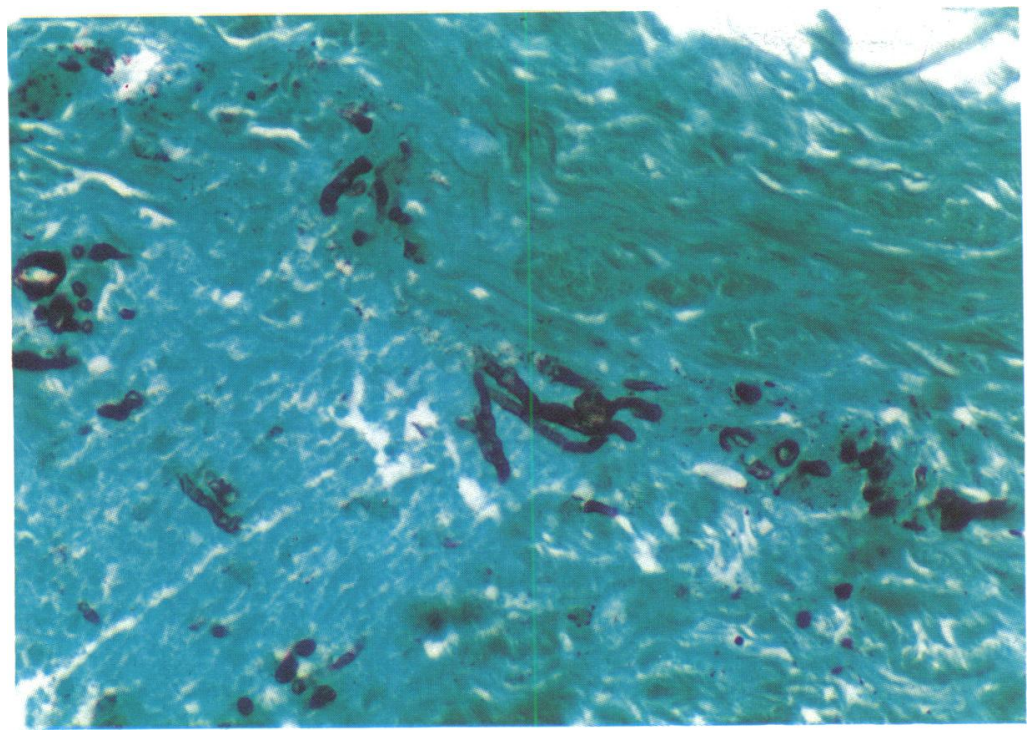

Figure 4 Hyphae in a section of sclera obtained at the time of sclerectomy (Gomori-methenamine-silver stain, $\times 22$.)

scleritis have been reported following pterygium surgery, ${ }^{3}$ scleral buckling procedures ${ }^{4}$ and cataract surgery. ${ }^{5}$ Trauma has been described as a cause for mycotic scleritis, ${ }^{67}$ but our patient did not recall any eye injury. Although these reported cases refer to exogenous infections, with agents other than $A$ niger, they do show similarities to our case. Clinically, severe headaches and periocular pain are common findings, with symptoms that wax and wane following use of corticosteroids. In all cases, a delay in diagnosis was encountered. We cannot exclude the possibility that an infection was introduced at the time of the subconjunctival injections of corticosteroids, but the scleritis was present before the first injection and the original presentation did not differ significantly from subsequent recurrences. Furthermore, the location of the injection was away from the location of the scleritis. As mentioned above, apart from trauma and surgery, a third source of infection can be endogenous spread from another infected site for example, following injecting drug use. ${ }^{12}$ In spite of an extensive examination, no source of infection could be identified in our patient. However, since our patient had a history of drug misuse, such an endogenous route related to drug misuse cannot be excluded. Since she had also been treated for automutilation of the breast, automutilation of the eye as a source of Aspergillus infection may have led to a primary scleritis, followed by a mycotic endophthalmitis. The isolation of a concomitant second infectious agent (the streptococcal infection) could also be due to manipulation of the ocular surface. It could, however, also be an opportunistic infection on an otherwise already traumatised ocular surface. Our conclusion is that despite the relatively rare occurrence infection with Aspergillus should be regarded as a possible cause of any unusual protracted scleritis.

The clinical photographs were taken by $\mathrm{Mr}$ Anthony Cubillas.

1 Stenson S, Brookner A, Rosenthal S. Bilateral endogenous necrotizing scleritis due to Aspergillus oryzae. Ann Ophthalmol 1982; 14: 67-72.

2 Doft BH, Clarkson JG, Rebell G, Forster RK. Endogenous Aspergillus endophthalmitis in drug abusers. Arch Ophthalmol 1980; 98: 859-62.

3 Margo CE, Polack FM, Mood CI. Aspergillus panophthalmitis complicating treatment of pterygium. Cornea 1988; 7: 285-9.

4 Lincoff HA, McLean JM, Nano H. Scleral abscess: I. A complication of retinal detachment buckling procedures. complication of retinal detachm

5 Carlson AN, Foulks GN, Perfect JR, Kim JH. Fungal scleritis after cataract surgery. Successful outcome using itraconazole. Cornea 1992; 11: 151-4.

6 Köllner H. Schimmelpilzerkrankung der Sklera. $Z$ Augenheilkd 1906; 16: 441-7.

7 Hemady R, De la Maza MS, Raizman MB, Foster CS. Six cases of scleritis associated with systemic infection. $A m \mathcal{F}$ Ophthalmol 1992; 114: 55-62.
Ophthalmology

\section{Department, Princess}

Alexandra Eye Pavilion,

Royal Infirmary,

Chalmers Street,

Edinburgh EH3 9HA

Z Butt

Neuropathology

Laboratory, Western

General Hospital,

Edinburgh

$\mathbf{J}$ W Ironside

Correspondence to:

Dr Z Butt.

Accepted for publication

22 February 1994

\title{
Superficial epithelioid schwannoma presenting as a subcutaneous upper eyelid mass
}

\author{
Z Butt, J W Ironside
}

We describe a case of superficial epithelioid schwannoma presenting as a mass in the superotemporal quadrant of the orbit. This was treated by local excision with no evidence of recurrence or metastases on follow up. To the best of our knowledge, this is the first case report of the tumour in this particular area.

\section{Case report}

A 55-year-old woman presented to our casualty department in 1989 with a 2 year history of an asymptomatic enlarging mass along the temporal aspect of her left upper eyelid. There was no significant medical or ocular history and the patient displayed none of the stigmata of neurofibromatosis.

On examination, corrected visual acuity was $6 / 6$, N5 right eye and 6/9,N5 left eye. Pupils were reactive to light, she had a full range of extraocular movements and there was no proptosis. Her discs were normal. She had a $1 \mathrm{~cm}$ diameter smooth firm mobile mass along the superotemporal quadrant of her orbit. Posterior 